\title{
Effect of Pantothenic Acid Deficiency on Lipid Metabolism in Yeast
}

\author{
II. Influence of Pantothenic Acid Deficiency on \\ Neutral Fats and Phospholipids
}

\author{
Yuji FurUkawa AND Shuichi KImUra ${ }^{1}$
}

Department of Food Chemistry, Faculty of Agriculture, Tohoku University, Sendai (Post No. 980)

(Received September 4, 1972)

\begin{abstract}
The incorporation of acetate-1- ${ }^{14} \mathrm{C}$ into lipid fractions in baker's yeast, Saccharomyces cerevisiae, grown in pantothenate-deficient $(10 \mu \mathrm{g} /$ liter $)$ medium, has been compared with that of the vitamin-sufficient $(200 \mu \mathrm{g} /$ liter $)$ yeast. In the vitamin-deficient yeast $(\mathrm{I})$ acetate- $1-{ }^{14} \mathrm{C}$ was incorporated mainly into unsaturated fatty acids e.g. $C_{16: 1}, C_{18: 1}$, whereas in the vitamin-sufficient yeast it was incorporated mainly into saturated fatty acids e.g. $C_{16: 0}, C_{18: 0,}$ (II) the incorporation of acetate- $1-{ }^{14} \mathrm{C}$ into sterol and triglyceride decreased and the level of free ${ }^{14} \mathrm{C}$-fatty acid was relatively higher than that in the vitamin-sufficient yeast. ${ }^{32} \mathrm{P}$-Phospholipid in yeast grown in medium containing ${ }^{32} \mathrm{P}$-phosphate was analyzed. In pantothenate-deficient yeast at the exponential phase, ${ }^{32} \mathrm{P}$-phosphatidyl choline and ${ }^{32} \mathrm{P}$-phosphatidyl ethanolamine were reduced one fourth and one third, respectively, of those in the vitamin-sufficient yeast. In pantothenatedeficient yeast much of oleic acid was found at the 2-position of phosphatidyl choline and at the 1-and 2-positions of phosphatidyl ethanolamine.
\end{abstract}

In a preceding paper (1), the influence of pantothenic acid $(\mathrm{PaA})$ deficiency on mitochondria in Saccharomyces cerevisiae was investigated morphologically with a electron microscope and the composition of lipid of the vitamin-deficient cells was analyzed in comparison with that of the vitamin-sufficient cells in order to seek the effect of $\mathrm{PaA}$ deficiency on lipid metabolism in this organism, and it was suggested that (I) $\mathrm{PaA}$ deficiency affected the membrane formation through the disturbance of lipid metabolism and (II) the organism played a certain economical control on the fatty acid synthesis under the vitamin-deficient condition. Proudlock et al. (2) indicated that mitochondrial metabolism in yeast was specifically affected by the depletion of unsaturated fatty acid. The ratios of unsaturated fatty acid over saturated fatty acid in $\mathrm{PaA}$ sufficient and deficient yeast were 2.65 and 11.64, respectively. Especially in the phospholipid fraction in the vitamin-deficient yeast this ratio was markedly high as shown previously (1). In this paper, the influence of $\mathrm{PaA}$ deficiency on the lipid synthesis and its constitution in Saccharomyces cerevisiae has been investigated.

\section{EXPERIMENTAL}

1. Microorganism and Culture Procedure A laboratory strain of Saccharomyces cerevisiae (3) originating from baker's yeast

\footnotetext{
1 古川勇次, 木村修一
} 
was grown in a synthetic medium described previously (1). In experiments to explove the ${ }^{32} \mathrm{P}$-incorporation into lipid fractions, yeast was grown in the same basal medium except that $176 \mu \mathrm{M}$ of $\mathrm{Na}_{2} \mathrm{HPO}_{4}$ was added. Each culture flask contained $100 \mathrm{ml}$ of the medium and 1 $\mathrm{mCi}$ of $\mathrm{H}_{3}{ }^{32} \mathrm{PO}_{4}$ (Daiichi Kagaku Co. Ltd.). The cells were cultivated aerobically on a shaker at $30^{\circ}$ until the exponential growth phase was reached.

\section{Lipid Extraction and Analysis}

Lipid was extracted and analyzed by the methods described previously (1). The methylesters of ${ }^{14} \mathrm{C}$-fatty acids were determined using a gas chromatograph (Shimazu GLC Type 4A) with a radiodetecter attached to it. Throughout the experiments a stainless steel column $(2,610$ $\mathrm{mm} \times 3 \mathrm{~mm} \phi$ ) packed with $15 \%$ DEGS on Shimalite (80 to 100 mesh) was used. Column temperature was set at $190^{\circ}$.

\section{Analysis of Fatty Acid in Phospholipid} Fraction

The fatty acid analysis of phosphatidyl choline and of phosphatidyl ethanolamine was carried out by the procedure described by Hildebrand et al. (4). These phospholipids were isolated by thin layer chromatography, and were eluted by chloroform-methanol $(1: 1)$. Then, fatty acids at the 2-position were selectively hydrolyzed by phospholipase A from snake venom (Shigma). The reaction mixture was directly applied to a silicic acid column (5). After free fatty acids were eluted with chloroform, phospholipid fractions (lyso-form phospholipid and unhydrolyzed phospholipid) were eluted with methanol. From the latter, the layer of a spot of lyso-phospholipid on thin layer chromatogram was collected separately and was eluted by methanol. The extracted lipid fractions were methylated with $\mathrm{BF}_{3}$-methanol method (6).

\section{RESULtS}

1. Incorporation of Acetate $-1{ }^{14} \mathrm{C}$ into $\mathrm{Li}$ pids and Fatty Acids

Table 1 shows the incorporation of acetate${ }_{1-1}^{14} \mathrm{C}$ into lipid fractions of $\mathrm{PaA}$ sufficient and deficient cells. The radioactivity incorporated
TABLE 1

Incorporation of Acetate-1-14C into lipids of PaA sufficient and deficient cells

\begin{tabular}{lcc}
\hline \hline & \multicolumn{2}{c}{ Radioactivity } \\
\cline { 2 - 3 } & $\begin{array}{c}\text { Sufficient } \\
\text { cells }\end{array}$ & $\begin{array}{c}\text { Deficient } \\
\text { cells }\end{array}$ \\
\hline Whole cells & \multicolumn{1}{c}{$c p m / m g$ dry cells } \\
Lipid fraction & 5,200 & 1,900 \\
& 4,500 & 1,300 \\
\hline
\end{tabular}

At the exponential growth phase the cells were harvested by centrifugation, washed three times with cold deionized water. A $50 \mathrm{ml}$ Erlenmyer flask contained $2.72 \mathrm{~g}$ (wet weight) of the washed cells, 11 mmoles glucose, $334 \mu$ moles of phosphate buffer, $\mathrm{pH} 5.45$, and $5 \mu \mathrm{c}$ of sodium acetate $-1{ }^{-14} \mathrm{C}$ in the total volume of $10 \mathrm{ml}$. After constant shaking for 3 hours at $30^{\circ}$ cells were harvested by centrifugation, and washed three times with cold deionized water. Lipids were then extracted and the radioactivity was measured with a liquid scintillation spectrometer GSL-112B (Kobe Kogyo Co, Ltd.).

TABLE 2

Acetate-1-14C incorporation into major fatty acids of PaA sufficient and deficient yeast

\begin{tabular}{|c|c|c|}
\hline \multirow{2}{*}{ Fatty acid } & \multicolumn{2}{|c|}{${ }^{14} \mathrm{C}$-fatty acid distribution* } \\
\hline & Sufficient & Deficient \\
\hline & \multicolumn{2}{|c|}{ per cent } \\
\hline $\mathrm{C}_{16: 0}$ & 31.7 & 17.8 \\
\hline $\begin{array}{l}16: 0 \\
C_{16: 1}\end{array}$ & 16.4 & 29.4 \\
\hline $\mathrm{C}_{18: 0}$ & 20.6 & 11.1 \\
\hline $\mathrm{C}_{18: 1}$ & 14.6 & 31.3 \\
\hline
\end{tabular}

* The relative radioactivity was calculated from each area of the radio-gas chromatographic peak.

into whole cells as well as into total lipid fraction decreased and was approximately one third of that obtained from the vitamin-sufficient cells. As shown in Table 2, in the vitaminsufficient cells acetate- $1-{ }^{14} \mathrm{C}$ was mainly incorporated into saturated fatty acids such as $\mathrm{C}_{16: 0}$ and $\mathrm{C}_{18: 0}$, while in the vitamin-deficient cells major radioactive products were found to be unsaturated fatty acids such as $\mathrm{C}_{16: 1}$ and $\mathrm{C}_{18: 1}$. The lipids extracted from these cells were analyzed by thin layer chromatography with silica gel G. The results summarized in Table 3 showed that in the vitamin-sufficient cells ${ }^{14} \mathrm{C}$-triglyceride was $33 \%$ of the total radioactive neutral fat, whereas in the vitamin-deficient cells this product was relatively small in quantity and free ${ }^{14} \mathrm{C}$-fatty acid was a major radio- 
TABLE 3

Distribution of radioactivities in neutral fat fractions

\begin{tabular}{lcc}
\hline \hline \multirow{2}{*}{ Lipid fraction } & \multicolumn{2}{c}{ Relative radioactivity } \\
\cline { 2 - 3 } & Sufficient & Deficient \\
\hline \multicolumn{2}{c}{ per cent } \\
Sterol, Diglyceride & 25.6 & 11.2 \\
Free fatty acid & 11.0 & 48.0 \\
Triglyceride & 33.0 & 14.5 \\
Unknown lipid & 1.8 & 7.7 \\
Sterol ester & 22.4 & 4.8 \\
\hline
\end{tabular}

The solvent for this chromatography was petroleum ether-ethylether-acetic acid $(82: 18: 1, \mathrm{v} / \mathrm{v})$. At room temperature the chromatograms took about 1 hour to run. After being dried the plates were developed with iodine vapour, and radioautography was carried out. The spots on the plates were identified from the authentic standard. Radioactivity was calculated by a thin layer chromatogram scanner (Aloka). Relative radioactivity was calculated by area on the chromatographic peak.

TABLE 4

Principal fatty acid composition in the free fatty acid fraction of PaA sufficient and deficient cells

\begin{tabular}{|c|c|c|}
\hline \multirow{2}{*}{ Fatty acid } & \multicolumn{2}{|c|}{ Relative amounts } \\
\hline & Sufficient & Deficient \\
\hline & \multicolumn{2}{|c|}{ per cent } \\
\hline $\mathrm{C}_{16: 0}$ & 21.7 & 10.0 \\
\hline $\mathrm{C}_{16: 1}$ & 21.0 & 15.7 \\
\hline $\mathrm{C}_{18: 0}$ & 18.2 & 9.1 \\
\hline $\mathrm{C}_{18: 1}$ & 34.5 & 64.2 \\
\hline
\end{tabular}

active product. Simultaneously, sterol, diglyceride and sterolester relatively decreased.

2. Fatty Acid Composition in PaA Sufficient and Deficient Cells

Table 4 shows the distribution of the principal fatty acid in free fatty acid fractions obtained from $\mathrm{PaA}$ sufficient and deficient cells. The samples for this study were separated by thin layer chromatography. In $\mathrm{PaA}$ deficient cells approximately $80 \%$ of the total fatty acid was recovered in unsaturated fatty acids, particularly in oleic acid fraction. Similar results were obtained with fatty acids obtained from total lipid and phospholipid as well as from neutral fat fractions.

3. Composition of Phospholipid Fractions Extracted from PaA Sufficient and Deficient Yeast

Table 5 shows the distribution of ${ }^{32} \mathrm{P}$-phos-
TABLE 5

Incorporation of ${ }^{32} P$-phosphate into phospholipid fractions of PaA sufficient and deficient cells

\begin{tabular}{|c|c|c|}
\hline \multirow[b]{2}{*}{ Phospholipid } & \multicolumn{2}{|c|}{ Radioactivity } \\
\hline & $\begin{array}{l}\text { Sufficient } \\
\text { cells }\end{array}$ & $\begin{array}{l}\text { Deficient } \\
\text { cells }\end{array}$ \\
\hline & \multicolumn{2}{|c|}{ cpm/mg dry cells } \\
\hline Phosphatidyl choline & 71,400 & 18,200 \\
\hline Phosphatidyl ethanolamine & 15,400 & 4,900 \\
\hline Phosphatidyl serine & 2,600 & 1,700 \\
\hline Phosphatidyl inositol* & 3,900 & 5,200 \\
\hline Lysophosphatidyl cholne & 4,300 & 8,100 \\
\hline Lysophosphatidyl ethanolamine & & 1.900 \\
\hline Phosphatidic acid or Cardiolipin* & 5,900 & 3.700 \\
\hline Other phospholipids & 19,500 & 21,300 \\
\hline
\end{tabular}

* Estimated phospholipid.

The phospholipid spots on a two-dimensional thin layer chromatogram $\left(0.01 \mathrm{M} \mathrm{Na}_{2} \mathrm{CO}_{3}\right.$ on silica gel $\left.\mathrm{G}\right)$ were identified by the staining with Dragendorff (7), Ninhydrin (8) and Zinzadze reagent (9). The first solvent was chloroform-methanol-acetic acid-water $(75: 45: 12: 4)$ and the second solvent was chloroformacetone-methanol-acetic acid-water $(50: 20: 10: 10: 5)$ (10). The radioactivity of spots on this chromatogram was directly mesured with a radiant ray scaler (Aloka model TDC 1).

phate in phospholipid fractions obtained from $\mathrm{PaA}$ sufficient and deficient yeast. The radioactive phosphatidyl choline and phosphatidyl ethanolamine were found to be $58 \%$ and 12.5 $\%$, respectively, of the total phospholipid fraction in normal cells. On the other hand, in the vitamin-deficient cells both phospholipids decreased approximately one fourth and one third, respectively. In contrast, radioactive lysophosphatidyl choline and a fraction which was tentatively identified as phosphatidyl inositol were found to increase in the vitamin-deficient cells.

\section{Fatty Acid Composition of Phosphatidyl} Choline and Phosphatidyl Ethanolamine

Table 6 shows the fatty acid composition of phosphatidyl choline and phosphatidyl ethanolamine from yeast grown in $\mathrm{PaA}$ sufficient and deficient media. Considerable differences on the fatty acid pattern at the respective position of these phospholipid molecules were observed between the vitamin-sufficient and deficient cells. The structure of phosphatidyl choline from yeast grown in $\mathrm{PaA}$ deficient medium was characterized by a large amount of saturated fatty acids $e . g . \mathrm{C}_{16}: 0, \mathrm{C}_{18: 0}$ in the 
TABLE 6

Major molecular species of phosphatidyl choline and phosphatidyl ethanolamine from yeast grown in PaA sufficient and deficient media

\begin{tabular}{|c|c|c|c|c|c|c|c|c|}
\hline \multirow{4}{*}{ Fatty acid } & \multicolumn{8}{|c|}{ Relative amounts } \\
\hline & \multicolumn{4}{|c|}{ Phosphatidyl choline } & \multicolumn{4}{|c|}{ Phosphatidyl ethanolamine } \\
\hline & \multicolumn{2}{|c|}{ 1-position } & \multicolumn{2}{|c|}{ 2-position } & \multicolumn{2}{|c|}{ 1-position } & \multicolumn{2}{|c|}{ 2-position } \\
\hline & Suff. & Def. & Suff. & Def. & Suff. & Def. & Suff. & Def. \\
\hline & \multicolumn{8}{|c|}{ per cent } \\
\hline$<\mathrm{C}_{16}$ & 2.7 & 10.4 & 14.1 & 1.5 & 2.7 & 2.8 & - & 1.1 \\
\hline $\mathrm{C}_{16: 0}$ & 41.4 & 29.2 & $\begin{array}{l}14.1 \\
21.0\end{array}$ & 3.4 & 41.3 & $\begin{array}{r}2.0 \\
13.8\end{array}$ & 3.9 & $\begin{array}{l}1.1 \\
7.3\end{array}$ \\
\hline $\mathrm{C}_{16: 1}$ & 34.5 & 11.4 & 11.8 & 12.9 & 44.5 & 37.9 & 13.5 & 10.5 \\
\hline $\mathrm{C}_{18: 0}$ & 10.2 & 19.8 & 10.4 & 1.0 & 2.6 & 5.0 & 1.2 & 2.3 \\
\hline $\mathrm{C}_{16: 1}$ & 8.5 & 11.9 & 19.7 & 80.4 & 6.7 & 33.4 & 77.3 & 76.6 \\
\hline Other & 2.7 & 6.9 & 23.0 & 0.8 & 2.2 & 7.1 & 4.1 & 2.2 \\
\hline
\end{tabular}

The detailed experimental conditions were given under "Experimental".

1-position, and unsaturated fatty acids e. $g$. $\mathrm{C}_{18: 1}, \mathrm{C}_{16: 1}$ in the 2-position. Especially, the percentage of oleic acid in the 2-position was strikingly high. In phosphatidyl ethanolamine, unsaturated fatty acids e.g. $\mathrm{C}_{18}:{ }_{1}, \mathrm{C}_{16: 1}$ at the 2-position were unaltered by $\mathrm{PaA}$ in the medium, but the relative amount of oleic acid at the 1-position was shown to be higher in the vitamin-deficient cells.

\section{Discussion}

In $\mathrm{PaA}$ deficient cells the incorporation of acetate- $1-{ }^{14} \mathrm{C}$ into the lipid fractions was markedly inhibited and major radioactive products were shown to be unsaturated fatty acids (Table $1,2)$. The results suggested that the desaturation of the fatty acid occurred with relatively high frequency in the vitamin-deficient cells. Furthermore, in the vitamin-deficient cells free fatty acid was a major portion of the neutral fat fraction, and sterol, diglyceride and triglyceride relatively decreased. From these phenomena it would be considered that the formation of acyl-CoA might be reduced because it was known that $\mathrm{PaA}$ is important in the lipid metabolism as a constituent of CoA. It was reported that in the normal yeast the amounts of phosphatidyl choline, phosphatidyl ethanolamine, phosphatidyl inositol and phosphatidyl serine were about $50,20,10$ and $10 \%$, respectively (11-13). In this experiment, the results obtained with regard to incorporation of ${ }^{32} \mathrm{P}$ phosphate into the phospholipid of the $\mathrm{PaA}$ sufficient cells were qualitatively in close agreement with these reports. However, as shown in Table 5, in the vitamin-deficient cells the proportion of radioactivity of phosphatidyl choline and phosphatidyl ethanolamine which are important phospholipids for formation of yeast biomembrane decreased and that of lysophosphatidyl choline increased. Lands and Merkl (14) have demonstrated that both 1-acyl and 2-acyl isomers of lysophosphatidyl choline can be acylated to phosphatidyl choline, and that the saturated fatty acids are predominant in the 1 position, whereas unsaturated fatty acids are predominant in the 2-position. In this experiment on yeast, as shown in Table 6, phosphatidyl choline and phosphatidyl ethanolamine of normal cells grown in $\mathrm{PaA}$ sufficient medium are acylated at 1-position not only by saturated fatty acids but also by unsaturated fatty acids such as $\mathrm{C}_{16: 1}$. And it was shown that oleic acid was dominant in the 2-position of phosphatidyl ethanolamine. However, in the vitamindeficient cells much of oleic acid was found at the 2-position of phosphatidyl choline and at the 1-position and the 2-position of phosphatidyl ethanolamine. It might be regarded that these abnormal proportions in phospholipid and these molecular species are dependent on the pattern of the fatty acid synthesis in $\mathrm{PaA}$ deficiency. Since it is well known that the lipid is an important component of the biomembrane structure, the change of the function related to the biomembrane e.g. mitochondrial function will be expected. Further work would be necessary 
to ascertain the mechanism of the phenomenon observed in $\mathrm{PaA}$ deficient cells on the fatty acid pattern.

\section{REFERENCES}

1. Furukawa, Y., and Kimura, S., J. Vitaminol., 17, 219 (1971).

2. Proudlock, J. W., Haslam, J. M., and Linnane, A.W., Biochem. Biophys. Res. Commun., 37, 847 (1969).

3. Sando, S., Sici. Rept. Tohoku Univ. fourth Ser., 22, 99 (1956).

4. Hildebrand, J.G., and Law, J.H., Biochemistry, 3, 1304 (1964).

5. Rhodes, D. N., and Dawson. R.M.C., Chromatographic and Electrophoretic Techniques (ed. Smith. I.), 1, 363, Interscience Publishers Inc., N.Y. (1960).
6. Metcalfe, L.D., and Schmitz, A.A., Anal. Chem., 33, 363 (1961).

7. Wheeldon, L. W., and Collins, F. D., Biochem. J., 70, 43 (1958).

8. Axelrod, J., Reichenthal, J., and Brodie, B. B., J. Biol. Chem., 204, 903 (1953).

9. Parker, F., and Peterson, F.W., J. Lipid Res., 6, 455 (1965).

10. Parsons, J. G., and Patton, S., J. Lipid Res., 8, 696 (1967).

11. Graff, G. L. A., Vanderkelen, B., Gueuning, C., and Humpers, J., C. R. Soc. Biol., 162, 1635 (1968).

12. Suomalainen, H., and Nurminen, T., Chem. Phys. Lipids, 4, 247 (1970).

13. Paltauf, F., and Johnston, J.M., Biochim. Biophys. Acta., 218, 424 (1970).

14. Lands, W.E. M., and Merkl, I., J. Biol. Chem., 238, 898 (1963). 